\title{
Attrition from care after the critical phase of severe pre-eclampsia and eclampsia: Insights from an intervention with magnesium sulphate in a primary care setting in northern Nigeria
}

\author{
Salisu Ishaku ${ }^{1^{*}}$, Babatunde Ahonsi $^{1}$, Jamilu Tukur $^{2}$, Oginni Ayodeji $^{1}$ \\ ${ }^{1}$ Population Council, Abuja, Nigeria; *Corresponding Author: sishaku@popcouncil.org \\ ${ }^{2}$ Department of Obstetrics \& Gynecology, Bayero University, Aminu Kano Teaching Hospital, Kano, Nigeria
}

Received 21 May 2013; revised 25 June 2013; accepted 18 July 2013

Copyright (C) 2013 Salisu Ishaku et al. This is an open access article distributed under the Creative Commons Attribution License, which permits unrestricted use, distribution, and reproduction in any medium, provided the original work is properly cited.

\section{ABSTRACT}

Background: Evidence has shown that Magnesium Sulphate $\left(\mathrm{MgSo}_{4}\right)$ is the gold standard for treating severe pre-eclampsia and eclampsia (SPE/E), and calls for its widespread use at all levels of health service delivery, including the primary care level. Objective: To determine if administering loading dose of $\mathrm{MgSO}_{4}$ on pregnant women with severe preeclampsia and eclampsia at primary care level would improve maternal and fetal outcomes. Method: Two sets of Primary Health Care (PHC) facilities were identified; one served as experimental one and the other as control. The community health extension workers (CHEWs) and the community health officers (CHOs) at the experimental PHCs were trained to administer the loading dose of $\mathrm{MgSO}_{4}$ for patients with SPE/E, in addition to other supportive treatments, before making a referral while the control PHCs did not give $\mathrm{MgSo}_{4}$, and neither administered diazepam as an alternative or no anti-convulsant at all, before making a referral to higher centers. Patients from the experimental and control facilities were prospectively monitored for fetal and maternal outcomes, namely maternal and fetal deaths, and for toxic effects of $\mathrm{MgSo}_{4}$ in the experimental arm. Results: Of the $150 \mathrm{pa}$ tients recruited, $82(55 \%)$ were in the experimental group and 68 (45\%) were in the control group. $90 \%$ of the patients in the experimental group defaulted after receiving the loading dose of $\mathrm{MgSo}_{4}$ while the remaining $10 \%$ completed the referral process. $44 \%$ of those in the control group completed the referral process. There were 3 maternal and 3 perinatal deaths, all in the control group. No adverse outcome (maternal or fetal death) or toxic effect was recorded among the recipients of $\mathrm{MgSo}_{4}$. Conclusion: This study suggests that lower-cadre health care professionals at PHCs can administer the loading dose of $\mathrm{MgSo}_{4}$ to SPE/E patients to improve maternal and fetal survival in critical states, without significant risk of adverse effects. However, the lack of compliance with referral processes remains a huge challenge.

Keywords: Magnesium Sulphate; Pre-Eclampsia Eclampsia; Primary Care Facilities; Attrition; Nigeria

\section{INTRODUCTION}

Hypertensive disorder in pregnancy, chiefly pre-eclampsia, is an obstetric complication which poses serious threat to lives and wellbeing of pregnant women and their babies. Although this pregnancy mal-adaptation does not show ethnic, racial or geographical predilection, with a global incidence uniformly around $10 \%$ [1], its progression to eclampsia occurs with increasing frequency among antenatal and parturient population in developing countries where antenatal care services are not easily accessible and/or are of poor quality [1]. Eclampsia is estimated to affect 50,000 women globally of whom over $90 \%$ lives in low-income countries. While the incidence of eclampsia has been shown to be relatively low (5.9 to 6.2 cases per 10,000 deliveries) in developed countries [2,3], incidence of up to 163 cases per 10,000 deliveries has been reported from developing countries, in particular Nigeria [4].

Facility-based studies in Kano and Jigawa States of 
Nigeria estimate eclampsia's contribution to maternal death as $31.1 \%$ and $46.1 \%$ respectively $[5,6]$. These observations were corroborated by findings from other parts of the country where mortality patterns associated with pre-eclampsia and eclampsia were investigated. For example, Efetie \& Okafor [7] reported a case-fatality rate of $28.3 \%$ and eclampsia-attributable mortality rate of 22.2/10,000 deliveries at the National Hospital, Abuja. MgSo4, being the gold standard for treating severe preeclampsia and eclampsia can improve adverse outcomes associated with SPE/E such as convulsion, recurrent convulsion, maternal and fetal mortality [1,2]. However, its utilization in Nigeria is restricted to secondary and tertiary level centers with presumed human and technical capacity to administer and monitor the drug in terms of safety and toxicity. This excludes a larger proportion of patients who live in rural settings where primary health facilities are the only available or easily accessible source of care. In Nigeria, (as in many developing countries) the Community Health Extension Workers (CHEWs) and the Community Health Officers (CHOs) are the main cadre of health personnel practicing in primary health care (PHCs) centers. They were not authorized to use magnesium sulphate due to the lack of formal training. Only nurses, midwives and doctors were allowed to administer $\mathrm{MgSo}_{4}$ as they had received formal training. This situation potentially has negative impact on women with $\mathrm{SPE} / \mathrm{E}$ who attend PHCs where they cannot receive full care.

In order to generate evidence to change policy, the Population Council, with support from MacArthur Foundation, implemented a one-year intervention research project (2010-2011) in Kano State, Nigeria to test the hypothesis that administering the loading dose of $\mathrm{MgSo}_{4}$ at primary care settings before embarking on further referral can substantially improve maternal and fetal outcomes in terms of morbidity and mortality. At the time of the intervention, all patients with SPE/E were referred from PHCs to secondary health centers without prior treatment with $\mathrm{MgSo}_{4}$. Ethical clearance for the study was obtained from the Population Council's Institutional Review Board in New York and the Kano State Health Services Management Board.

\section{METHODOLOGY}

The study was prospectively conducted in Kano State, Nigeria from September 2010 to August 2011. Two arms of Primary Health Care (PHC) facilities were identified; one as experimental and the other as control. Of the 10 identified PHCs, 5 were experimental (Indabo, Gwagwarwa, Kibiya, Saye and Shanono districts) and the other 5 as control (Yelwa, Rurum, Darki, Shuwaki and Getso districts). Both the experimental and control PHCs received SPE/E patients, administered initial stabilizing treatment (anti-hypertensive and other supportive treatments) before referral to pre-determined referral centers. There were 5 referral centers (General Hospitals in Gwarzo, Bichi, Wudil, Rano and the Murtala Muhammed Specialist Hospital Kano), each receiving from 2 PHCs (one experimental and one control). At the secondary health centers, further care was continued. All the secondary health centers administered $\mathrm{MgSo}_{4}$, and delivered the women either vaginally or via caesarean section depending on clinical indications. The distance from the PHCs to their respective referral centers is fairly equal; between 20 - 25 kilometers.

All the health workers at the experimental PHCs were trained to recognize patients with SPE/E. They were also trained to administer the loading dose of 10 grams of $\mathrm{MgSo}_{4}$ intramuscularly for patients with severe PE/E after obtaining the appropriate consent from the patients or their informants, if patient is unconscious, in addition to other supportive treatments, before referral. They also received training on the detection of toxic effects of $\mathrm{MgSo}_{4}$ and the administration of its antidote (Calcium gluconate). The training was conducted by two consultant obstetricians working at the Department of Obstetrics and Gynecology of Aminu Kano Teaching Hospital in Kano.

The experimental facilities were also supplied with $\mathrm{MgSo}_{4}$, Calcium gluconate, blood pressure measuring equipments, urine dipsticks and patella hammers. On the other hand, the control PHCs did not administer $\mathrm{MgSo}_{4}$, but either administered diazepam as an alternative or no anti-convulsant at all. Because it was anticipated that occasionally, some families may not be able to transfer their patients in a timely manner due to transportation costs, and ambulance service is not generally available, arrangements were made for prompt transfer of such patients using taxis provided through a collaboration with the Kano state branch of the National Union of Road Transport Workers (NURTW), unless the patients and/or relations declined. The two sets of patients were tracked for their ability to complete the referral process and for subsequent monitoring for fetal and maternal outcomes, and for unwanted complications associated with $\mathrm{MgSo}_{4}$ administration in the experimental arm. On a monthly basis, two consultant obstetricians with specialist training in monitoring and evaluation visited all the PHCs and the referral secondary facilities to ensure that the study was going as planned.

\section{DATA MANAGEMENT}

Data were collected with a patient questionnaire completed by designated health workers that attended to the SPE/E patients, both at the PHCs and the referral secondary health centers. The patient questionnaire collected data such as socio-demographic characteristics, patient 
history, facility of first admission, next referral center and clinical management and outcomes for each SPE/E patient. The data entry was done with Epidata Version 3.1 (270108) and analyzed with SPSS version 17. Descriptive analysis using frequencies and percentages was conducted; thereafter, bivariate analysis (using Chi-square test) and multivariate analysis (using binary logistic regression) were conducted to determine factors associated with difference in default rate in referral between the patients that received loading dose at PHC and those that did not. Statistical significance was set at $\mathrm{p}$ value of $<0.05$. Fischer Exact test was also used to test the difference in maternal and fetal outcomes between the patients that received loading dose at PHCs and those that did not at $\mathrm{p}<0.05$.

\section{FINDINGS}

A total of 150 patients with SPE/E were recruited for the study. Eighty two (55\%) and 68 (45\%) patients were recruited from the experimental and control facilities respectively. Fifty eight (39\%) of the patients were younger than 20 years of age and 93 (61\%) were in monogamous relationships while $44 \%$ were primigravidae. Up to $71(47 \%)$ of the patients had no formal education (Table 1). Of all the 150 patients that were referred to the designated General Hospitals, about 75\% defaulted. Default rate was much higher among those in the experimental arm who received the loading dose of $\mathrm{MgSo}_{4}$ at PHCs (90\%) than those in the control PHCs (56\%). After adjusting for other variables (age, marital status, education and parity), the adjusted odds ratios showed that those that received the loading dose at PHCs were about nine times more likely (Adjusted OR $=9.27$; $95 \% \mathrm{CI}=$ $3.20,26.85)$ to default than those that did not receive the loading dose (Table 2).

Among those who completed the referral process, and on whom information is complete (25\%), 24 delivered by spontaneous vaginal delivery, 3 were delivered by a caesarean section and for the remaining 3 patients; the mode of delivery was not indicated. There were 3 maternal and 3 fetal deaths, all in the control arm (Table 1). No incidence of toxic effect of $\mathrm{MgSo}_{4}$ administration was observed among the experimental group. All the CHEWs and CHOs who provided services at the experimental facilities expressed satisfaction and were highly comfortable with their ability to administer the loading of $\mathrm{MgSo}_{4}$ in these settings.

\section{DISCUSSION}

This study showed that $39 \%$ of the patients were below the age of 20, and all undergoing their first pregnancies. This observation is in line with global experience of higher preponderance of pre-eclampsia among first time mothers [3,4]. Early marriage and teenage
Table 1. Maternal characteristics and outcomes of the patients.

\begin{tabular}{|c|c|}
\hline Variables & $\mathrm{N}(\%)$ \\
\hline \multicolumn{2}{|l|}{ Age } \\
\hline $15-19$ & $58(38.7)$ \\
\hline$\geq 20$ & 92(61.3) \\
\hline \multicolumn{2}{|l|}{ Marital status } \\
\hline Married monogamous & $93(62.0)$ \\
\hline Married polygamous & $57(38.0)$ \\
\hline \multicolumn{2}{|l|}{ Education } \\
\hline None & $71(47.3)$ \\
\hline Have formal education & $79(52.7)$ \\
\hline \multicolumn{2}{|l|}{ Parity } \\
\hline None & $66(44.0)$ \\
\hline$\geq$ one & $84(56.0)$ \\
\hline \multicolumn{2}{|l|}{ Had a loading dose from PHC } \\
\hline No & $68(45.3)$ \\
\hline Yes & $82(54.7)$ \\
\hline \multicolumn{2}{|l|}{ Maternal outcome } \\
\hline Death & $3(2.0)$ \\
\hline Alive & $34(22.7)$ \\
\hline Unknown & $113(75.3)$ \\
\hline \multicolumn{2}{|l|}{ Foetal outcome } \\
\hline Death & $3(2.0)$ \\
\hline Alive & 28(18.7) \\
\hline Unknown & $119(79.3)$ \\
\hline \multicolumn{2}{|l|}{ Referral } \\
\hline Completed & $38(25.3)$ \\
\hline Defaulted & $112(74.7)$ \\
\hline Total & $150(100.0)$ \\
\hline
\end{tabular}

pregnancy are common place in rural Nigeria, especially in the northern region, with an earlier study suggesting that $45 \%$ of adolescents girls aged 15 - 19 have already begun childbearing [8]. It is also known that pre-eclampsia is more common in women undergoing their first childbirth even in developed countries [3]. In this study, $44 \%$ of the patients were having their first pregnancies and childbirths.

Several studies from northern Nigeria such as Tukur et al. [9] have shown positive association between educational attainment of women and utilization of essential preventive maternal and child health services, including the uptake of antenatal care services; an opportunity for detecting and averting high-risk pregnancies such as severe pre-eclampsia, eclampsia and other complications. Similarly, findings in this study showed that up to $47 \%$ of these eclamptic patients have not attained any form of formal education. These results further highlight the roles of teenage pregnancy, nulliparity and low education of women in the social etiogenesis of pregnancy complications and poor maternal health outcomes. 
Table 2. Logistic regression of referral performance of patients from $\mathrm{PHC}$ to GH.

\begin{tabular}{|c|c|c|c|c|}
\hline & \multicolumn{4}{|c|}{$\begin{array}{l}\text { Referral performance } \\
\text { of patients }\end{array}$} \\
\hline & $\begin{array}{c}\text { Completed } \\
\mathrm{n}(\%)\end{array}$ & $\begin{array}{c}\text { Defaulted } \\
\text { n(\%) }\end{array}$ & $\begin{array}{l}\text { Chi-square } \\
\text { p-value }\end{array}$ & Adjusted OR \\
\hline \multicolumn{5}{|l|}{$\begin{array}{l}\text { Received loading } \\
\text { dose at PHC }\end{array}$} \\
\hline No & $30(44.1)$ & $38(55.9)$ & 0.000 & 1.00 \\
\hline Yes & $8(9.8)$ & 74(90.2) & & $\begin{array}{c}9.27 \\
(3.20,26.85)^{*}\end{array}$ \\
\hline \multicolumn{5}{|l|}{ Age } \\
\hline $15-19$ & $19(32.8)$ & $39(67.2)$ & 0.097 & 1.00 \\
\hline$\geq 20$ & 19(20.7) & 73(79.3) & & $\begin{array}{c}2.70 \\
(0.84,8.69)\end{array}$ \\
\hline \multicolumn{5}{|l|}{ Marital } \\
\hline Married monogamous & $27(29.0)$ & $66(71.0)$ & 0.183 & 1.00 \\
\hline Married polygamous & 11(19.3) & $46(80.7)$ & & $\begin{array}{c}1.89 \\
(0.72,4.93)\end{array}$ \\
\hline \multicolumn{5}{|l|}{ Had formal education } \\
\hline No & $27(38.0)$ & $44(62.0)$ & 0.001 & 1.00 \\
\hline Yes & 11(13.9) & $68(86.1)$ & & $\begin{array}{c}5.02 \\
(1.74,14.44)^{*}\end{array}$ \\
\hline \multicolumn{5}{|l|}{ Parity } \\
\hline None & 25(37.9) & $41(62.1)$ & 0.002 & 1.00 \\
\hline One or more & $13(15.5)$ & $71(84.5)$ & & $\begin{array}{c}3.66 \\
(1.23,10.89)^{*}\end{array}$ \\
\hline
\end{tabular}

${ }^{*} \mathrm{p}$-value is $\mathrm{p}<0.05$.

Findings revealed that $75 \%$ of the patients did not complete the referral process from the referring PHCs to the receiving secondary health facilities. This is especially the case in the experimental arm (90\%) where patients received the loading dose of $\mathrm{MgSo}_{4}$ (Table 2). Magnesium sulphate administration in patients with severe preeclampsia and eclampsia is known to be associated with a rapid but temporary improvement in symptoms. $\mathrm{MgSo}_{4}$ aborts seizures in almost all patients and some would even regain consciousness. While resuscitation of eclamptic patients with $\mathrm{MgSo}_{4}$ is desirable and potentially lifesaving in rural settings, the maximum maternal and fetal benefits are only obtained when the patient is further referred to higher centers with better facilities for further management and monitoring of the condition. From the available evidence, and by intuition, $\mathrm{MgSo}_{4}$ administration with its instant ameliorative effects might have given the false signal to the patients and their families that all is well, and that further referral was unnecessary.

The eclampsia trial collaborative group [10] has demonstrated the efficacy of $\mathrm{MgSO}_{4}$ in averting, aborting and preventing recurrent convulsion, major morbidity and mortality in eclampsia. These benefits were equally derived with $\mathrm{MgSo}_{4}$ in real world use [11]. Since in this en- vironment, patients mostly seek care mainly because of the convulsion, the cessation of convulsion following $\mathrm{MgSo}_{4}$ could send wrong signals to patients' families that the problem is resolved, and further hospital care may not be necessary. This underscores the value of educating patients and families from the outset that $\mathrm{MgSo}_{4}$ does not cure the disease, and that eventual delivery and monitoring until full recovery will be needed. Counseling on this from the beginning would improve adherence, especially in patients requiring further management at higher referral centers. Program managers and policy-makers who are introducing task-shifting or task-sharing with $\mathrm{MgSO}_{4}$ in rural areas must be cognizance of this unhealthy phenomenon.

Although this study addressed this counseling need from the beginning, failure to complete the referral process persisted, indicating the need for further community mobilization and community-level action which has been shown to be successful in the fight against post-partum hemorrhage in northern Nigeria [12]. Individuals and communities have a right and responsibility to play a role in improving their health and wellbeing [13]. Convulsion and unconsciousness are two of the main reasons for presenting at the facility in much of rural northern Nigeria [9]. This calls for further actions in terms of patient and family education for the entire community to appreciate the different ramifications of the disease. The communities need to know that the ultimate treatment for severe pre-eclampsia and eclampsia is the delivery of the baby, and subsequently the placenta, not just aborting convulsion and regaining of consciousness. Understanding this would enhance compliance, strengthen the referral process and improve materno-fetal survival and wellbeing.

However, this default phenomenon was also observed in the control arm (56\%). It is, therefore, unlikely that the temporary improvement in symptoms following $\mathrm{MgSo}_{4}$ administration is solely responsible. Again, this attrition occurred despite having a robust arrangement in place to transport patients to the referral centers free of charge. Therefore, other socio-cultural, economic and religious factors including chronic poverty might be remotely contributive to not achieving the intended continuum of care, including linkages across levels of care, which is increasingly considered as one of the core principles of maternal, newborn and child health initiatives [14].

The role of establishing emergency community transport system is one area that has recently occupied a pride of place in the fight against maternal mortality in developing countries. Both Fiagbe et al. [15] and Jeff Turner [16] have described an increase in health care utilization when an affordable transport service is available in all efforts to reduce maternal mortality. In other words, patients would be more willing to utilize lifesaving maternal health services when a means of transportation is 
available. In this study, however, despite making adequate arrangements for emergency transport services, most of the patients did not complete the referral process in both the experimental and control arms, but especially in the experimental group, suggesting that lack of transport means is not the only incriminating factor, at least in patients with eclampsia and severe pre-eclampsia.

Of all the women who were treated with $\mathrm{MgSo}_{4}$ and successfully tracked, no single case of $\mathrm{MgSo}_{4}$ toxicity was reported. This is not unexpected since this study utilized 10 grams intra-muscular loading dose of $\mathrm{MgSo}_{4}$ and no further dose was given before referral. Previous studies in which low doses of $\mathrm{MgSo}_{4}$ were used showed that toxic effects are not as common as frequently feared $[17,18]$. In addition, the CHEWs and CHOs in this study did not report any difficulty with the administration of $\mathrm{MgSo}_{4}$ both in terms of competence or the fear of side effects. This clearly negates the fear that $\mathrm{MgSo}_{4}$ is too complex a drug to be used at the lowest level of care in developing countries.

Experience using $\mathrm{MgSo}_{4}$ by lower-cadre health care providers in rural settings is scarce. A prior study that assessed the efficacy of intramuscular loading dose of $\mathrm{MgSo}_{4}$ to treat SPE/E in Nigeria has confirmed successes with this regimen at a tertiary level [19], but not at primary care setting. However, successful deployment of task-shifting with other essential maternal and child health interventions, in Nigeria and elsewhere, lays credence to the potential benefits that can accrue if task-shifting/ task-sharing is widely practised. For example, Warriner et al. [20] has reported similar level of effectiveness and safety in Nepal where early trimester medical abortion was performed by midlevel medical providers as compared with when the intervention was administered by a doctor.

On the balance of evidence, from this and other studies, $\mathrm{MgSo}_{4}$ can be safely administered the PHC level by lower cadre health care personnel if properly trained and supervised. This paper calls for rapid expansion of the use of $\mathrm{MgSo}_{4}$ in the lowest health care facilities in developing countries in order to reach the poorest of the poor who need it most. However, challenges remain.

Firstly, local officials must ensure that $\mathrm{MgSo}_{4}$ is available and accessible at all times in PHC facilities in keeping with the standard of PHCs to provide the six Basic Emergency Obstetrics Care (BEmOC) services, including availability of anticonvulsant; e.g., $\mathrm{MgSo}_{4}$ in this case. Presently, stock-out of $\mathrm{MgSo}_{4}$ at both the primary and secondary facilities is a frequent occurrence, and mars all efforts to ensure regular utilization of $\mathrm{MgSo}_{4}$ in rural settings.

Secondly, despite having a robust emergency transport arrangement in place, many patients were unable to complete the referral process. While the temporary improve- ment in symptoms upon receiving $\mathrm{MgSo}_{4}$ is partly responsible for this high default rate, other factors such as the fear of further expenditure at the higher level of care by the patients' families may be contributory. This may be especially true in Nigeria with high level of poverty with annual per capita income of $\$ 2240$ [21]. In most cases, SPE/E occurs as an emergency giving the typically poor patients and their families no room to mobilize the needed money to pay for treatment. This indicates the need for continuously advocating for the implementation of the "Birth Preparedness and Complications Readiness" strategy. The implication for women not accounted for through default after receiving $\mathrm{MgSo}_{4}$ loading dose injection is very grave. The seizure may have reoccurred at home, or the woman or her baby or both might have died as well. Unless such patients and their babies are accounted for, the benefits of deploying $\mathrm{MgSo}_{4}$ at this level of care would be clouded with uncertainty. And since withholding $\mathrm{MgSo}_{4}$ at the primary care level due to fear of attrition is not an option, further research is recommended to unravel the mysteries behind patients' disappearance.

\section{CONCLUSION AND RECOMMENDATION}

This study suggests that with appropriate training and supervision, lower-cadre health care professionals can safely administer $\mathrm{MgSo}_{4}$ to treat severe pre-eclampsia and eclampsia without significant toxic effects in primary care settings in developing countries. A major challenge that should be considered when stabilizing eclamptic women with $\mathrm{MgSo}_{4}$ in primary care settings in developing countries is the failure to complete the referral process to higher centers where definitive treatment can be obtained. Improvement in signs and symptoms of eclampsia following $\mathrm{MgSo}_{4}$ administration passes a wrong signal to patients' families that all is well. The consequence of not being able to account for women after receiving the loading dose of $\mathrm{MgSo}_{4}$ is very grave. Program planners must ensure that appropriate information is available through community mobilization and work out modalities that would address the militating effects of poverty, ignorance, and other socio-cultural factors on the referral process.

\section{REFERENCES}

[1] World Health Organization (2011) Recommendations for prevention and treatment of pre-eclampsia and eclampsia; Geneva.

http:www.who.int/publications/2011/9789241548335_en g.pdf

[2] Zwart, J.J., Richters, A., Ory, F., de Vries, J.I., Bloemenkamp, K.W. and van Roosmalen, J. (2008). Eclampsia in 
the Netherlands. Obstetrics \& Gynecology, 112, 820. doi:10.1097/AOG.0b013e3181875eb3

[3] Liu, S., Joseph, K.S., Liston, R.M., Batholomew, S., Walker, M., Kirby, R.S. and Kramer, M.S. (2011) Incidence, risk factors and associated complications of eclampsia. Obstetrics \& Gynecology, 118, 987.

doi:10.1097/AOG.0b013e31823311c1

[4] Eke, A.C., Ezebialu, I.U. and Okafor, C. (2011) Presentation and outcome of eclampsia at a tertiary center in south east Nigeria-A 6-year review. Hypertens Pregnancy, 30, 125. doi:10.3109/10641955.2010.525283

[5] Adamu, Y.M., Hamisu, M.S., Nalini, S. and Greg, R.A. (2003) Maternal mortality in northern Nigeria: A population-based study. European Journal of Obstetrics \& Gynaecology and Reproductive Biology, 109, 153-159. doi:10.1016/S0301-2115(03)00009-5

[6] Tukur, J., Rabi'u, A. and Gill, K.S. (2008) Pattern of eclampsia in a tertiary health facility situated in a semi-rural town in Northern Nigeria. Annals of African Medicine, 6, 164-167. doi:10.4103/1596-3519.55703

[7] Efetie, E.R. and Okafor, U.V. (2007) Maternal outcomes in eclamptic patients in Abuja, Nigeria: A 5-year review. Nigerian Journal of Clinical Practice, 10, 309-313.

[8] National Population Commission (NPC) [Nigeria] and ICF Macro (2009) Nigeria demographic and health survey 2008. National Population Commission and ICF Macro, Abuja.

[9] Tukur, J., Ahonsi, B., Salisu, I.M., Idowu, A., Ekechi and O., Oginni, A.B. (2012) Maternal and fetal outcomes after introduction of magnesium suphate for treatment of preeclampsia and eclampsia in selected secondary facilities: A low-cost intervention. Maternal and Child Health Journal, 15, 1.

[10] The Eclampsia Trial Collaborative Group (1995) Which anticonvulsant for women with eclampsia? Evidence from the collaborative eclampsia trial. Lancet, 345, 1455-1463.

[11] McDonald, S.D., Lutsiv, O., Dzaja, N. and Duley, L. (2012) A systematic review of maternal and fetal outcomes following magnesium sulphate for pre-ecalmpsia/eclampsia in real-world use. International Journal of Gynecology and Obstetetrics, 118, 90-96. doi:10.1016/j.ijgo.2012.01.028

[12] Prata, N., Ejembi, C., Fraser, A., Shittu, O. and Minkler, M. (2012) Community mobilization to reduce post-partum hemorrhage in home births in northern Nigeria. So- cial Science and Medicine, 74, 1288-1296. doi:10.1016/j.socscimed.2011.11.035

[13] World Health Organization (1978) Declaration of Alma Ata. International conference on primary health care. http:www.who/int/publications/almaata_declaration_en.p df

[14] Alexander, M.M. and Rose, N. (2012) Survival of neonates in rural Tanzania. Does place of delivery or continuum of care matters? BMC Pregnancy and Child Birth, 12, 18. doi:10.1186/1471-2393-12-18

[15] Fiagbe, P., Asamoah, D. and Oduro, F.T. (2012) Assessing the role of transportation in the achievement of maternal mortality reduction in Ghana. International Journal of Business and Management, 7, 5. doi:10.5539/ijbm.v7n5p256

[16] Turner, J. (2013) Maternal health and transport: A need for action.

http//www4.worldbank.org/afr/ssatp/Resources/HTML/G ender-RH/Resourcedocument/issue and strategy papers/ Maternal Health/IMSH1 MH and Transport Turner

[17] Begum, R., Begum, A., Johanson, R., Ali, M.N. and Akhter, S. (2001) A low-dose (“DHAKAR”) magnesium sulphate regime for eclampsia. Acta Obstetricia et Gynecologica Scandinavica, 80, 998-1002.

[18] Omu, A.E., Al-Harmi, J., Vedi, H.L., Mlechkova, L., Sayed, A.F. and Al Ragum, N.S. (2008) Magnesium sulphate therapy in women with pre-eclampsia and eclampsia in Kuwait. Medical Principles and Practice, 17, 227-232. doi:10.1159/000117797

[19] Okunsanya, B.O., Garba, K.D. and Ibrahim, H.M. (2012) The efficacy of intra-muscular loading dose of $\mathrm{MgSo}_{4}$ in severe pre-eclampsia/eclampsia at a tertiary referral centre in northwest Nigeria. The Nigerian Postgraduate Medical Journal, 19.

[20] Warriner, I.K., Dualao, W., My Huong, N.T., Kusum, T., Anand, T., Iqbal, S., David, T.B. and Olav, M. (2011) Can midlevel health-care providers administer early medical abortion as safely and effectively as Doctors? A randomized controlled equivalence trial in Nepal. doi:10.1016/S0140-6736(10)62229-5

[21] The Population Reference Bureau (2012) World population data sheet.

http//www.prb.org/pdf12-population-data-sheet_eng.pdf 